\title{
Leakage-free DOX/PEGylated chitosan micelles fabricated via facile one-step assembly for tumor intracellular pH-triggered release
}

Xubo Zhao, Yuejun Yao, Kun Tian, Tingting Zhou, Xu Jia, Jiagen Li, Peng Liu*

State Key Laboratory of Applied Organic Chemistry and Key Laboratory of

Nonferrous Metal Chemistry and Resources Utilization of Gansu Province, College of Chemistry and Chemical Engineering, Lanzhou University, Lanzhou 730000, China

\begin{abstract}
A general strategy was developed to fabricate the chitosan-based micelles as smart drug delivery system (DDS) for anti-cancer drug doxorubicin (DOX), via modulating the feeding ratio of PEG ( $\left.\mathrm{PEG}_{2000}-\mathrm{CHO}\right)$ and molecular weight of chitosan. Typically, benefiting from the solubility of chitosan in media with different $\mathrm{pH}$ values as an "off-on" switch, the DOX/CS ${ }_{100 \mathrm{~K}}-\mathrm{PEG}_{2}$ micelles possess spherical core with a narrow dispersed diameter of $64 \mathrm{~nm}$ and regular shell with a thickness of $14 \mathrm{~nm}$ in $\mathrm{pH} 7.4$

PBS. Interestingly, the DOX/CS-PEG micelles exhibited drug leakage-free behavior in a physiological environment, with a cumulative release ratio of only $2.32 \%$ under pH 7.4 PBS, while achieving rapid drug release and a cumulative release ratio of $72.76 \%$ in the intracellular microenvironment. Moreover, the micelles transformed into the water-soluble $\mathrm{CS}_{100 \mathrm{~K}}-\mathrm{PEG}_{2}$ after the $\mathrm{pH}$-triggered intracellular release of
\end{abstract}

\footnotetext{
* Corresponding author at: State Key Laboratory of Applied Organic Chemistry and Key Laboratory of Nonferrous Metal Chemistry and Resources Utilization of Gansu Province, College of Chemistry and Chemical Engineering, Lanzhou University, Lanzhou 730000, China. Fax: +86 931 8912582. E-mail address: pliu @ 1zu.edu.cn (P. Liu).
} 
DOX, it makes them easy to be biodegraded and eliminated by metabolic system. As revealed by MTT assays and CLSM images, DOX could be efficiently and rapidly transported into cell nuclei of tumor cells and showed significant cell inhibition. The simple fabrication and excellent properties make them intelligent and favorable on-demand DDS in cancer treatment.

Keywords: drug delivery system; drug leakage-free; chitosan micelles; pH-triggering; controlled release

\section{Introduction}

Cancer is still one of the murderers endangering human health, and either the incidence or mortality of cancers is ever-increasing. Chemotherapy has attracted extensive attention as a highly efficient approach in cancer treatment. However, severe side effects and limited therapeutic efficiency in field of clinical current chemotherapy are two main obstacles existing for cancer therapy, which has restricted therapeutic effect as well as aroused abominable status in patients [1]. To reduce severe side effects and improve therapeutic efficiency, the physicochemical differences (such as acidity [2], overexpressed proteins and enzymes [3] and abnormal temperature gradients [4]) between the normal tissues and microenvironment or endosomes and lysosomes of the tumor tissues have been utilized to design intelligent and favorable drug delivery platform. 
Unfortunately, most DDSs showed the uncontrollable drug leakage in the circulatory system before the nanocarriers have entered the tumor tissues [5]. Taking doxorubicin (DOX) as an example, it has been mostly loaded onto the drug delivery system (DDS) via the non-covalent interaction, such as electrostatic interaction, hydrogen bonds, hydrophobic interaction, $\pi-\pi$ stacking, or combinations of more than one ways above. In the simulated normal physiological media, $20-40 \%$ or even higher of DOX could be released from the DOX-loaded DDS with those non-covalent interactions, due to the certain solubility of DOX in $\mathrm{pH} 7.4$ media [6].

To further reduce severe side effects and improve therapeutic efficiency, recent efforts have been turned to the drug loading method, namely the interaction between drugs and DDS. DOX has been covalently conjugated onto the DDS via the acid-labile [7-11] or reductant-cleavable [12-14] linkages. The prodrugs are relatively stable during blood circulation, but quickly dissociate to achieve burst release of DOX toward exposing acidic lysosomes in tumor tissues. But even so, the DOX leakage from the prodrugs was more than $5 \%$, and in some case $>20 \%[14,15]$, and up to $40 \%$ [16]. Furthermore, for some prodrugs conjugated via acid-labile linkage [9] and all those with reductant-cleavable disulfide linkage, DOX was released in the form of its derivatives [12-14].

In comparison, designing the smart DDS with more accurate response seems to be a more efficient strategy to reduce severe side effects, by reducing the drug leakage in circulation system to the greatest extent. Tang et al coated $\mathrm{pH}$-responsive polymer shell chitosan/poly (methacrylic acid) (CS-PMAA) on mesoporous silica 
nanoparticles (MSN) through the facile in situ polymerization method to control the DOX release in different $\mathrm{pH}$ media [17]. Chen et al designed bioresponsive polymer-mesoporous silica nanoparticles (PAA-PCL-MSNs) with function akin to an “AND" logic gate for targeted drug delivery with $<5 \%$ of final DOX leakage after 50 $\mathrm{h}$ incubation [18]. Luo et al designed a new type of peptide-functionalized MSN with a plug-gate nanovalve (PGN) for targeted drug release in cancer cells without obvious release of DOX at pH 7.4 [19]. Most recently, Dai et al designed novel gold-shell nanoparticles (pH-GSNPs) exhibiting drug leakage-free behavior in a physiological environment [20].

Recently, chitosan and its derivatives in the forms of nanoparticles and micelles have been widely investigated for tumor chemotherapy and diagnosis due to their unique characteristics, such as biocompatibility, biodegradability, remarkable cell membrane penetrability, $\mathrm{pH}$-dependent therapeutic unloading, ease to multi-functionalization, and so on [21], especially the PEGylated chitosan copolymers [22]. And for most of the chitosan and its derivatives-based nanoparticles and micelles, the drug carriers were fabricated at first, and then the drugs were loaded [23-26]. Because of it nature of polycation, the targeted $\mathrm{pH}$-mediated intracellular release of methotrexate disodium (MTX) has been reported with the crosslinked chitosan microgels as vehicle, benefiting from the swelling of chitosan in different media [27].

In the present work, a facile strategy was developed to fabricate the drug leakage-free DDS by means of the solubility of chitosan in different $\mathrm{pH}$ media as an 
"off-on" switch (Scheme 1). As a natural biocompatible weak polybase with pKa of approximately 6.5 [28], chitosan could deprotonate in slightly basic media ( $\mathrm{pH} 7.4)$, resulting from the increase in its hydrophobicity. On the contrary, the water-solubility of chitosan is enhanced because of protonation in slightly acidic media, especially $\mathrm{pH}$ value $<5.0$ [29]. Herein, chitosan was PEGylated via the reduction of Schiff's base between PEG and chitosan to form well-defined core-shell structure for compactly encapsulating anticancer drug DOX due to the hydrophobicity of chitosan and DOX [30], and prolonged blood circulation of doxorubicin [25]. This amphiphilic copolymer is a reasonably amphiphilic precursor for molecular self-assembly by hydrophobic interaction in PBS. More importantly, the typical DOX/CS ${ }_{100 \mathrm{~K}}-\mathrm{PEG}_{2}$ micelles possess the "off-on" switchable release properties in the different $\mathrm{pH}$ media. The micelle dissociates to burst release DOX in response to acidic lysosomes. Meantime, the DOX/CS $100 \mathrm{~K}-\mathrm{PEG}_{2}$ micelles transform into the water-soluble $\mathrm{CS}_{100 \mathrm{~K}}-\mathrm{PEG}_{2}$, which could be eliminated by metabolic system, after the $\mathrm{pH}$-triggered intracellular release of DOX.

\section{Experimental}

\subsection{Materials and reagents}

Three chitosan (CS, degree of deacetylation: 95\%) samples with different viscosity-average molecular weights $\left(3.0 \times 10^{5}, 1.0 \times 10^{5}\right.$ or $\left.5 \times 10^{4}\right)$ were provided by Weifang Sea Source Biological Products Co., Ltd. Single aldehyde-terminated poly(ethylene glycol) ( $\left.\mathrm{PEG}_{2000}-\mathrm{CHO}\right)$ was purchased from Beijing Kaizheng Bioeng. 
Doxorubicin hydrochloride $(\mathrm{DOX} \cdot \mathrm{HCl})$ was obtained from Beijing Huafeng United Technology Co., Ltd. Furthermore, $\mathrm{NaCNBH}_{3}$, and acetic acid were analytic reagent grade from Tianjin Chem. Co. Ltd. and used without further purification. Deionized water was used throughout

\subsection{PEGylation of chitosan}

To regulate morphology and endow biocompatibility of the DOX delivery system, different amounts of $\mathrm{PEG}_{2000}-\mathrm{CHO}$ were used to modify chitosan with different viscosity-average molecular weight $\left(3.0 \times 10^{5}, 1.0 \times 10^{5}\right.$ or $\left.5 \times 10^{4}\right)($ Scheme 2$)$, as summarized in Table 1 . In a typical procedure, ${ }^{30} 0.165 \mathrm{~g}$ of chitosan $\left(1.0 \times 10^{5}\right)$ was dissolved in $20 \mathrm{~mL}$ of $1 \mathrm{M}$ acetic acid aqueous solution. $20 \mathrm{~mL}$ of methanol and 1.300 $\mathrm{g}$ of $\mathrm{PEG}_{2000}-\mathrm{CHO}$ were added into the solution under magnetic stirring at room temperature overnight. Subsequently, the $\mathrm{pH}$ value of the mixture was adjusted from original 4.90 to 6.24 with $1 \mathrm{M} \mathrm{NaOH}$ aqueous solution and continually kept for 30 min. Then $0.102 \mathrm{~g}$ of $\mathrm{NaCNBH}_{3}(1.625 \mathrm{mM})$ was added into the solution by dropwise, and the reduction reaction was performed under vigorous stirring at nitrogen atmosphere for $8 \mathrm{~h}$. The obtained pre-product was concentrated under reduce-pressure state by vacuum pump, and transferred into dialysis tube (MWCO: 12 000) against abundant deionized water for $72 \mathrm{~h}$ to remove the unreacted $\mathrm{PEG}_{2000}-\mathrm{CHO}$. Finally, the obtained product was lyophilized and stored at $4{ }^{\circ} \mathrm{C}$.

\subsection{Drug loading and triggered release}


The DOX-loading was conducted via a facile in-situ micellization approach. Typically, $40.0 \mathrm{mg} \mathrm{CS}{ }_{100 \mathrm{k}}-\mathrm{PEG}_{2}$ was introduced into $1 \mathrm{mg} / \mathrm{mL}$ of DOX aqueous solution (40.0 $\mathrm{mL}$ ), and then the $\mathrm{pH}$ value of solution was adjusted to 6.8 for drug-loading with the aid of ultrasound. Subsequently, the obtained mixtures were transferred into dialysis tube (MWCO: 12 000) against abundant PBS (pH 6.8) for 7 days to remove the excess DOX. Finally, the DOX/CS $100 \mathrm{~K}-\mathrm{PEG}_{2}$ was lyophilized and stored at $4{ }^{\circ} \mathrm{C}$. Other DOX-loaded micelles were prepared by the same procedure (Table 1). Next, the UV-vis spectrophotometer was determined the drug concentration in the supernatant solution at $480 \mathrm{~nm}$ to assess the encapsulation efficiency and the drug-loading capacity, by comparing the drug concentrations before and after loading.

Subsequently, to assess release behavior of the DOX-loaded $\mathrm{CS}_{100 \mathrm{k}}-\mathrm{PEG}_{2}$ micelles in stimulating both normal tissues and microenvironment of tumor tissues, the DOX-loaded $\mathrm{CS}_{100 \mathrm{k}}-\mathrm{PEG}_{2}$ micelles were dispersed into $10 \mathrm{~mL}$ PBS $(\mathrm{pH}=7.4, \mathrm{pH}=6.5$, and $\mathrm{pH}=5.0$ ). In the coming step, the suspension of the DOX-loaded $\mathrm{CS}_{100 \mathrm{k}}-\mathrm{PEG}_{2}$ micelles was transferred into dialysis tubes (MWCO of 12 000) and immersed in 120 $\mathrm{mL}$ of related PBS at $37{ }^{\circ} \mathrm{C}$ for controlled release. The DOX concentration in the dialysate was detected with a UV spectrophotometer at certain time intervals.

\subsection{Cell toxicity and cellular uptake}

MTT assay was carried out to assess the biocompatibility of the $\mathrm{CS}_{100 \mathrm{~K}}-\mathrm{PEG}_{2}$ with HepG2 cells, and the cytotoxicity of the DOX/CS ${ }_{100 K}-\mathrm{PEG}_{2}$ micelles and free DOX for HepG2 cells were evaluated by incubation of HepG2 cells in nutrient solution 
supplemented with 10\% FBS (fetal bovine serum).

The cellular uptake was conducted with confocal laser scanning microscopy (CLSM) (LYMPUS FV-1000) using HepG2 cells after $12 \mathrm{~h}$ and $24 \mathrm{~h}$ of incubation. The location of intracellular fluorescence was validated with excitation wavelengths of $480 \mathrm{~nm}$ for DOX and $405 \mathrm{~nm}$ for Hoechst. These specific steps were referred to previous report [6].

\subsection{Instruments and characterization}

Elemental analysis of $\mathrm{C}, \mathrm{N}$, and $\mathrm{H}$ of CS-PEG was performed on an Elementar vario EL instrument (Elementar Analysensysteme GmbH, Munich, Germany).

A Bruker IFS 66 v/s infrared (IR) spectrometer (Bruker, Karlsruhe, Germany) was used for the Fourier transform IR spectroscopy analysis in the range of 400-4000 $\mathrm{cm}^{-1}$ with a resolution of $4 \mathrm{~cm}^{-1}$, with $\mathrm{KBr}$ pellet technique.

The morphologies of the DOX/CS-PEG micelles were characterized using a JEM1200 EX/S transmission electron microscope (TEM), with the samples dispersed in water and then deposited on a copper grid covered with a perforated carbon film.

The hydrodynamic diameters and distributions of the DOX/CS-PEG micelles were determined using the dynamical mode [dynamic light scattering (DLS)] on a Light Scattering System BI-200SM device (Brookhaven Instruments) equipped with a BI-200SM goniometer, a BI-9000AT correlator, a temperature controller, and a coherent INOVA $70 \mathrm{C}$ argon ion laser at $20^{\circ} \mathrm{C}$. DLS measurements are performed using a $135-\mathrm{mW}$ intense laser excitation at $514.5 \mathrm{~nm}$ at a detection angle of $90^{\circ}$ using 
the emulsion directly at $25^{\circ} \mathrm{C}$.

All fluorescence spectra were obtained with a PerkinElmer LS 55 luminescence spectrophotometer equipped with a $1.0 \mathrm{~cm}$ quartz cell. The fluorescence spectra of the DOX/CS-PEG micelles were conducted in the wavelength range of 500-650 nm upon excitation at $495 \mathrm{~nm}$ at different $\mathrm{pH}$ values. Typically, $1.0 \mathrm{~mL}$ of $10 \mu \mathrm{g} / \mathrm{mL}$ DOX/CS ${ }_{100 \mathrm{~K}}-\mathrm{PEG}_{2}$ micelles aqueous dispersion was added into the color comparison tubes, and the synchronous fluorescence spectra were recorded in the wavelength range of $480-680$ with $\Delta \lambda$ of $50 \mathrm{~nm}$.

The controlled release behaviors of the DOX/CS $100 \mathrm{~K}-\mathrm{PEG}_{2}$ micelles were measured with a PerkinElmer Lambda 35 UV-vis spectrometer (PerkinElmer Instruments, USA) at room temperature.

\section{Results and discussion}

\subsection{Synthesis of CS-PEG}

Both excellent biocompatibility and controllable morphology are extremely important for DDS. Therefore, PEG was utilized to modify the backbone of chitosan to enhance hydrophilicity. And chitosan with different average molecular weights was chosen to regulate size of the DDS for obtaining a general method. The synthetic approach of the CS-PEG is shown in Scheme 2: PEGylation of chitosan via Schiff's base formed between the amino group of chitosan and the aldehyde group of $\mathrm{PEG}_{2000}-\mathrm{CHO}$, and the reduction of the Schiff's base [30]. The PEG segments were introduced onto the skeleton of chitosan to make the PEGylated chitosan favorable 
morphology-controllable in the range of $\mathrm{pH} 7.4$ to 5.0. In the IR spectrum of the typical $\mathrm{CS}_{100 \mathrm{~K}}-\mathrm{PEG}_{2}$, after the PEGylation with $\mathrm{PEG}_{2000}-\mathrm{CHO}$, the $\mathrm{C}-\mathrm{O}-\mathrm{C}$ stretching vibration of PEG appeared at $1108 \mathrm{~cm}^{-1}$, while the characteristic peak at $1596 \mathrm{~cm}^{-1}$ of the $\mathrm{N}-\mathrm{H}$ in-plane deformation and vibration in amide group of chitosan was still remained (Figure 1A). Furthermore, the characteristic peak at $2900 \mathrm{~cm}^{-1}$ of C-H stretching enhanced obviously. It demonstrated that the PEG brushes have been effectively conjugated onto the skeleton of chitosan via reduction of Schiff's base. This result also indicated partial amine groups of chitosan were retained, which are contributed to preserve the $\mathrm{pH}$-response of chitosan.

The PEG content in $\mathrm{CS}_{50 \mathrm{~K}}-\mathrm{PEG}, \mathrm{CS}_{100 \mathrm{~K}}-\mathrm{PEG}_{1}, \mathrm{CS}_{100 \mathrm{~K}}-\mathrm{PEG}_{2}, \mathrm{CS}_{100 \mathrm{~K}}-\mathrm{PEG}_{3}$, and

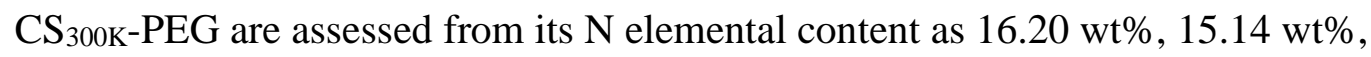
$27.12 \mathrm{wt} \%, 38.00 \mathrm{wt} \%$, and $13.21 \mathrm{wt} \%$, respectively. With the increasing of feeding molar ratio of PEG from $25 \%$ to $45 \%$ and $65 \%$, the PEG content in the $\mathrm{CS}_{100 \mathrm{~K}}-\mathrm{PEG}_{1}$, $\mathrm{CS}_{100 \mathrm{~K}}-\mathrm{PEG}_{2}$, and $\mathrm{CS}_{100 \mathrm{~K}}-\mathrm{PEG}_{3}$ increased from $15.14 \mathrm{wt} \%$ to $27.12 \mathrm{wt} \%$, and 38.00 $\mathrm{wt} \%$. This phenomenon is attributed to the increase in the $\mathrm{PEG}_{2000}-\mathrm{CHO}$ feeding ratio. Meantime, in comparison with the high PEG contents of the $\mathrm{CS}_{50 \mathrm{~K}}-\mathrm{PEG}$ of $16.12 \mathrm{wt} \%$, the $\mathrm{CS}_{100 \mathrm{~K}}-\mathrm{PEG}_{1}$ and $\mathrm{CS}_{300 \mathrm{~K}}-\mathrm{PEG}$ showed lower PEG contents of $15.14 \mathrm{wt} \%$, and $13.21 \mathrm{wt} \%$, respectively. It's worth noting that increasing of the average molecular weight of chitosan led to decreasing of PEG contents in $\mathrm{CS}_{100 \mathrm{~K}}-\mathrm{PEG}_{1}$ and $\mathrm{CS}_{300 \mathrm{~K}}-\mathrm{PEG}$. The reason might be that increasing of molecular chain of chitosan enhances the viscosity of mixture and further weak the activity of polymer chain in solution as well as then increased the steric hindrance effect to reduce reactivity of between the 
aldehyde group of the $\mathrm{PEG}_{2000}-\mathrm{CHO}$ and the amine groups in chitosan. Taken together, a series of the CS-PEG are efficiently synthesized though precise control of $\mathrm{PEG}_{2000}-\mathrm{CHO}$ feeding ratio and viscosity-average molecular weight of chitosan.

\subsection{Preparation of DOX/CS-PEG micelles}

To achieve the less leakage of anticancer-drug in normal tissues, DOX is encapsulated into the CS-PEG micelles via hydrophobic interaction by a facile in-situ micellization approach. In the DOX/CS-PEG micelles, DOX is utilized as hydrophobic section to form core, the $\mathrm{pH}$-responsive skeleton of chitosan is used as a $\mathrm{pH}$-modulated shell to prevent leakage of DOX, and the hydrophilic PEG brushes are utilized to endow biocompatibility of the DDS and regulate the morphology of the nanoplatform. The hydrophobic properties of the chitosan can form a hydrophobic interaction with DOX. Therefore, DOX could be noncovalently encapsulated on the $\mathrm{CS}_{100 \mathrm{~K}}-\mathrm{PEG}_{2}$ micelles by a hydrophobic interaction in aqueous solution at related $\mathrm{pH}$ values with the aid of slight ultrasonication. Considering the enhanced water-solubility of DOX [6] and the deprotonation of chitosan (pKa of approximately 6.5) [28], the $\mathrm{pH}$ value of mixture of DOX and $\mathrm{CS}_{100 \mathrm{~K}}-\mathrm{PEG}_{2}$ was adjusted from $\mathrm{pH} 5.0$ to $\mathrm{pH} 6.8$ to enhance the hydrophobility of DOX and $\mathrm{CS}_{100 \mathrm{~K}}-\mathrm{PEG}_{2}$. At the same time, the PEG moieties keep hydrophilic from beginning to end at the adjusted process of $\mathrm{pH}$ value of the mixture. Thus the DOX/CS ${ }_{100 \mathrm{~K}}-\mathrm{PEG}_{2}$ micelles were synergistically formed in aqueous solution via hydrophobic interaction between DOX and the PEGylated 
chitosan, and then the encapsulation of DOX has been efficiently realized without any adscititious organic solvent at vigorously magnetic stirring.

After DOX-loading, the characteristic peak at $1596 \mathrm{~cm}^{-1}$ and $1108 \mathrm{~cm}^{-1}$ appeared in the IR spectra of the DOX/CS $100 \mathrm{~K}-\mathrm{PEG}_{2}$. And the characteristic peaks at $1730 \mathrm{~cm}^{-1}$ and $1073 \mathrm{~cm}^{-1}$ were ascribed to the carbonyl asymmetric stretching and $\mathrm{C}=\mathrm{C}$ of benzene stretching vibration of DOX in the DOX/CS $100 \mathrm{~K}-\mathrm{PEG}_{2}$ [31]. Owing to the introduction of DOX molecules in the CS-PEG, the DOX/CS-PEG possessed strong UV-vis absorption and fluorescence emission under excitation of certain wavelength. As a result, the product become dark red compared to the original white one. The UV-vis absorption of DOX in various DOX/CS-PEG micelles was detected at $490 \mathrm{~nm}$ to $510 \mathrm{~nm}$ (Figure 1B). The shifts in the peaks of various DOX/CS-PEG micelles might be resulted from the hydrogen bond interaction between DOX molecule and polymer. Exhilaratingly, the DOX/CS-PEG micelles exhibited maximum fluorescent emission at around $560 \mathrm{~nm}$ and $590 \mathrm{~nm}$ with $495 \mathrm{~nm}$ excitation (Figure1 C), indicating the presence of DOX in these micelles. Furthermore, double fluorescence channel of DOX in the DOX/CS-PEG micelles is observed [32]. Taken above analysis into consideration, it could be concluded that DOX molecule has been successfully encapsulated into the CS-PEG micelles, and the physical encapsulation didn't influence the UV-vis absorption and fluorescence emission of DOX to conveniently monitor tumor tissues by real-time fluorescent imaging.

The DOX-loading capacity (\%) and encapsulation efficiency (\%) of the $\mathrm{CS}_{50 \mathrm{k}}-\mathrm{PEG}$, $\mathrm{CS}_{100 \mathrm{~K}}-\mathrm{PEG}_{1}, \mathrm{CS}_{100 \mathrm{~K}}-\mathrm{PEG}_{2}, \mathrm{CS}_{100 \mathrm{~K}}-\mathrm{PEG}_{3}$, and $\mathrm{CS}_{300 \mathrm{k}}-\mathrm{PEG}$ micelles, which are 
determined with standard curve by UV-vis spectrometer at $485.00 \mathrm{~nm}$, were 0.4821 $\mathrm{mg} / \mathrm{mg} \pm 0.0130 \mathrm{mg} / \mathrm{mg}, 0.4423 \mathrm{mg} / \mathrm{mg} \pm 0.0096 \mathrm{mg} / \mathrm{mg}, 0.3214 \mathrm{mg} / \mathrm{mg} \pm 0.0231$ $\mathrm{mg} / \mathrm{mg}, 0.1470 \mathrm{mg} / \mathrm{mg} \pm 0.0043 \mathrm{mg} / \mathrm{mg}$, and $0.1681 \mathrm{mg} / \mathrm{mg} \pm 0.0044 \mathrm{mg} / \mathrm{mg}$, and $48.21 \% \pm 1.30 \%, 44.23 \% \pm 0.96 \%, 32.14 \% \pm 2.31 \%, 14.70 \% \pm 0.43 \%$, and $16.81 \% \pm$ $0.44 \%$, respectively. Interestingly, the DOX contents in various DOX/CS-PEG showed inverse correlation in comparison with the PEG content because of increasing of hydrophilic capability of PEG segments to decline hydrophobic interaction between chitosan and DOX molecules. In addition, it is strict that this above DOX contents are obtained by means of dialysis method under abundant deionized water to remove adsorbent DOX through hydrogen bond interaction between drug molecules and segments of polymer to decline leakage of DOX during long-term cycle of blood circulation.

As shown in Figure 2 ( $a, b$ and $c$ ), with the increasing of average molecular weight of chitosan, the diameter of the DOX/CS $50 \mathrm{k}-\mathrm{PEG}$ micelles, DOX/CS $100 \mathrm{~K}-\mathrm{PEG}_{1}$ micelles and DOX/CS $300 \mathrm{k}-\mathrm{PEG}$ micelles increased from $54.67 \pm$ $11.43 \mathrm{~nm}$ to $101 \pm 18.76 \mathrm{~nm}$ and $158 \pm 14.52 \mathrm{~nm}$. Furthermore, the hydrodynamic diameter of the DOX/CS $50 \mathrm{k}-\mathrm{PEG}$ micelles, $\mathrm{DOX} / \mathrm{CS}_{100 \mathrm{~K}}-\mathrm{PEG}_{1}$ micelles and DOX/CS $300 \mathrm{k}-\mathrm{PEG}$ micelles also increased from approximately $111 \mathrm{~nm}$ to $175 \mathrm{~nm}$ and $295 \mathrm{~nm}$ with increasing of average molecular weight of chitosan. More importantly, the morphology of the DOX/CS-PEG micelles exhibited spherical shape in PBS $(\mathrm{pH}=6.8)$. Both the TEM and DLS analysis demonstrated that the size of the DOX/CS-PEG micelles could be regulated by altering the average 
molecular weight of chitosan. Meantime, different amount of PEG-CHO was utilized to modify the backbone of chitosan for investigating the micelle morphology. By increasing of PEG from $15.14 \mathrm{wt} \%$, to $27.12 \mathrm{wt} \%$ and $38.00 \mathrm{wt} \%$, the morphology of the DOX/CS ${ }_{100 k}-P E G$ micelles changed from spheres with protuberance, to spheres with the contrast of uniformly, and to vesicle.

Furthermore, the $\mathrm{N}$ elemental contents of the various CS-PEG were determined for evaluating the PEG contents and the results are presented in Table 1. The surface structure of the DOX/CS $100 \mathrm{k}-\mathrm{PEG}_{2}$ and DOX/CS $\mathrm{D}_{100 \mathrm{k}}-\mathrm{PEG}_{3}$ became smooth and orderliness in comparison with the DOX/CS $100 \mathrm{k}-\mathrm{PEG}_{1}$, with the increase of contents of PEG brushes. In particular, the DOX/CS ${ }_{100 \mathrm{k}}-\mathrm{PEG}_{2}$ micelles might preferably encapsulate DOX by comparison of DOX/CS ${ }_{100 k}-P^{2} G_{1}$ with protuberance of structure and DOX/CS $100 \mathrm{k}-\mathrm{PEG}_{3}$ with vesicle of structure. Actually, these differential presentations are attributed to different contents of hydrophobic DOX and hydrophilic PEG on the skeleton of chitosan. The DOX/CS ${ }_{100 K}-P_{3} G_{3}$ micelles showed "bubbly" shape with the average diameter of $96.89 \pm 38.43 \mathrm{~nm}$ due to the hydrophilic PEG brushes distributing both sides of skeleton of chitosan, with increasing amount of PEG to $38.00 \mathrm{wt} \%$. Furthermore, high content of the hydrophilic PEG brushes could weak the hydrophobic interaction of DOX in the DOX/CS ${ }_{100 \mathrm{~K}}-\mathrm{PEG}_{3}$ micelles resulting from hydrophilicity of both sides of skeleton of chitosan. More importantly, the fuzzy boundaries between hydrophobic and hydrophilic domains easily form different self-assembly structure, as well as resulting in morphological transition as 
previously reported [33].

Additionally, DLS technique was employed to evaluate the particle dispersion index (PDI) of all DOX/CS-PEG micelles as shown in Figure 3. The DOX/CS-PEG micelles have excellent PDI, besides the DOX/CS ${ }_{100 \mathrm{~K}}-\mathrm{PEG}_{3}$ because of hydrophilic increasing of both sides of the skeleton of chitosan. This hydrophilic increasing of skeleton of chitosan might lead to fuzzy boundaries between the hydrophobic and hydrophilic domains resulting in "bubbly" shape with unfavorable PDI.

Owing to the favorable surface structure and diameter, and relatively high encapsulation efficiency and drug-loading capacity, the DOX/CS $100 \mathrm{~K}-\mathrm{PEG}_{2}$ micelles were chosen as the desired DDS for further exploration. With changing the media $\mathrm{pH}$ value from 6.8 to 7.4 , the core-shell structure of the DOX/CS $100 \mathrm{~K}-\mathrm{PEG}_{2}$ micelles could be observed in Figure 3. The DOX/CS ${ }_{100 K}-\mathrm{PEG}_{2}$ micelles have spherical core with a diameter of around $64 \mathrm{~nm}$ and regular shell with a thickness of approximately of $14 \mathrm{~nm}$. The well-defined structure was attributed to the hydrophobic skeleton of chitosan, hydrophobic DOX molecules and hydrophilic PEG brushes in the $\mathrm{pH} 7.4$ media. The DOX/CS $100 \mathrm{~K}-\mathrm{PEG}_{2}$ micelles could keep their core-shell structure in $\mathrm{pH} 7.4$ PBS, whereas in pH 5.0 PBS, their well-defined structure was destroyed as shown in Figure $2 \mathrm{f}$. The reason is that the protonation of the amine groups of chitosan in slightly acidic media ( $\mathrm{pH} 5.0$ ), resulting in an increase of the hydrophilicity of chitosan. This is consistent with observation of DLS for dissociation of the $\mathrm{DOX} / \mathrm{CS}_{100 \mathrm{~K}}-\mathrm{PEG}_{2}$ micelles, implying that most $\mathrm{DOX} / \mathrm{CS}_{100 \mathrm{~K}}-\mathrm{PEG}_{2}$ micelles are successfully dissociated in the slight acidic media. On the basis of above analysis and 
discussion, the well-defined core-shell structured $\mathrm{DOX} / \mathrm{CS}_{100 \mathrm{~K}}-\mathrm{PEG}_{2}$ micelles with pH-response have been successfully prepared.

To further preferably understand the $\mathrm{pH}$-responsive behavior of the DOX/CS ${ }_{100 \mathrm{~K}}-\mathrm{PEG}_{2}$ micelles, the responsive behavior of the $\mathrm{CS}_{100 \mathrm{~K}}-\mathrm{PEG}_{2}$ was evaluated by TEM in desired $\mathrm{pH}$, such as $\mathrm{pH} 7.4$ and 5.0. As shown in Figure 4, the dissociation of $\mathrm{CS}_{100 \mathrm{~K}}-\mathrm{PEG}_{2}$ micelles were observed with the $\mathrm{pH}$ value mixture of $\mathrm{CS}_{100 \mathrm{~K}}-\mathrm{PEG}_{2}$ from 7.4 to 5.0 by adjusted with the diluted $\mathrm{HCl}$ solution. This phenomenon revealed that the $\mathrm{DOX} / \mathrm{CS}{ }_{100 \mathrm{~K}}-\mathrm{PEG}_{2}$ micelles possessed desirable $\mathrm{pH}$-responsive behavior in the range of $\mathrm{pH} 7.4$ to 5.0.

\subsection{In vitro release performance}

As a $\mathrm{pH}$-responsive chitosan based drug delivery system, the $\mathrm{DOX} / \mathrm{CS}_{100 \mathrm{~K}}-\mathrm{PEG}_{2}$ micelles not only exhibited a relatively stable structure in normal tissues but also a disassociated structure in response to typical conditions in tumor tissues because of the protonation of amine group of chitosan in slightly acidic pH 5.0. Meantime, therapeutically on-demand release of DOX from the DOX/CS $100 \mathrm{~K}-\mathrm{PEG}_{2}$ micelles is predicted to be accelerated under acidic medium in the cytoplasm and endolysosomes of tumor tissues. Considering this difference, therefore, the in vitro release performance of DOX from DOX/CS ${ }_{100 \mathrm{~K}}-\mathrm{PEG}_{2}$ micelles was evaluated under certain conditions such as $\mathrm{pH} 7.4$ (stimulating normal tissues), $\mathrm{pH} 6.5$ (stimulating microenvironment of tumor tissues), and $\mathrm{pH} 5.0$ (stimulating cytoplasm and endolysosomes of tumor tissues), as shown in Figure 1 (D). 
The cumulative release ratio from the DOX/CS ${ }_{100 \mathrm{~K}}-\mathrm{PEG}_{2}$ micelles was only $2.32 \%$ at $\mathrm{pH} 7.4$ and $9.16 \%$ at $\mathrm{pH} 6.5$ for $60 \mathrm{~h}$. These results indicated that the DOX/CS ${ }_{100 \mathrm{~K}}-\mathrm{PEG}_{2}$ micelles possessed highly stability at physiological $\mathrm{pH}$ media. More importantly, this tiny release of DOX from the DDS, which is also much less than those from the pro-drugs with acid-liable or reduction-cleavable conjugations, attributes to reduce the severe toxic side effect of anticancer drugs to normal tissues of patients. To imitate the intracellular trafficking process of tumor tissues, drug cumulative release experiments were performed at $\mathrm{pH} 5.0$ (stimulating the acidic endosomal compartments). In comparison with the drug leakage-free behavior at $\mathrm{pH}$ 7.4, the cumulative release of DOX from the DOX/CS $100 \mathrm{~K}-\mathrm{PEG}_{2}$ micelles was conducted at $\mathrm{pH}$ 5.0. Notably, the cumulative release of DOX from the DOX/CS ${ }_{100 \mathrm{~K}}-\mathrm{PEG}_{2}$ micelles was apparently accelerated in elevated $\mathrm{pH}$ values (pH 5.0) as well as cumulative release ratio reached $73.35 \%$ for $60 \mathrm{~h}$. These results revealed that the premature release of DOX was obviously reduced because of the highly stability of the DOX/CS ${ }_{100 \mathrm{~K}}-\mathrm{PEG}_{2}$ micelles at $\mathrm{pH} 7.4$ to realize safely long-term cycle during blood circulation. Furthermore, rapid and burst release of DOX from the DOX/CS ${ }_{100 \mathrm{~K}}-\mathrm{PEG}_{2}$ micelles at $\mathrm{pH} 5.0$ came true. A key feature of the $\mathrm{CS}_{100 \mathrm{~K}}-\mathrm{PEG}_{2}$ micelles is the protonation of amine group of chitosan upon exposing to at acidic environment. In acidic media, the amino groups of both $\mathrm{CS}_{100 \mathrm{~K}}-\mathrm{PEG}_{2}$ and $\mathrm{DOX}$ protonate, and the enhanced repulsive force between them should contribute to the increase in the cumulative release of DOX. Besides, after the $\mathrm{pH}$-triggered release of DOX at slight acidic media, the DOX/CS ${ }_{100 \mathrm{~K}}-\mathrm{PEG}_{2}$ micelles transformed into the 
water-soluble $\mathrm{CS}_{100 \mathrm{~K}}-\mathrm{PEG}_{2}$, that could be degraded, and then eliminated by metabolic system. On the basis of above analysis, the engineered DOX/CS $100 \mathrm{~K}-\mathrm{PEG}_{2}$ micelles with $\mathrm{pH}$-responsive structure, drug leakage-free characteristic in a physiological environment, and burst release properties at stimulating tumor tissues, namely, the tumor microenvironment-responsive triggered release performance, were achieved.

\subsection{Cellular toxicity and uptake}

To assess the engineered rationality of the $\mathrm{DOX} / \mathrm{CS}_{100 \mathrm{~K}}-\mathrm{PEG}_{2}$ micelles, it is crucial to evaluate cytocompatibility via a general acceptable MTT for HepG2 cell (a general model of parenchymal cells in the liver). The viability of the HepG2 cells exceeded $89 \%$ at the all tested concentrations $(0-80 \mu \mathrm{g} / \mathrm{mL})$ after $24 \mathrm{~h}$ of incubation (Figure 5), revealing that the $\mathrm{CS}_{100 \mathrm{~K}}-\mathrm{PEG}_{2}$ micelles have good biocompatibility toward HepG2 cells.

To realize clinical application, an excellent drug delivery system should possess not only favorable biocompatibility in normal tissues but also a rapid release upon exposure to tumor tissues. To determine the therapeutic effect of the $\mathrm{pH}$-responsive DOX/CS ${ }_{100 K}-\mathrm{PEG}_{2}$ micelles, the in vitro inhibition growth of HepG2 was evaluated the by MTT assays, compared with free DOX. As shown in Figure 5, the DOX/CS ${ }_{100 \mathrm{~K}}-\mathrm{PEG}_{2}$ micelles presented apparently cytotoxic effects in all tested concentration range. For comparison, free DOX was introduced to as control group. Obviously, introduction of DOX pronouncedly inhibited viability of HepG2 cells with increasing DOX concentration up to $10.0 \mu \mathrm{g} / \mathrm{mL}$. The inhibition growth degree of free 
DOX was obviously higher than the DOX/CS ${ }_{100 \mathrm{~K}}-\mathrm{PEG}_{2}$ micelles, resulting from the lower cumulative release ratio of DOX (53.36 wt $\%$ for around 24 h). Furthermore, the DOX/CS 100K $_{-}-\mathrm{PEG}_{2}$ micelles possessed the same killing capacity for HepG2 cell as free DOX in all the tested concentration range.

As a model system, HepG2 cells were incubated with the DOX/CS $100 \mathrm{~K}-\mathrm{PEG}_{2}$ micelles in the different time intervals. The confocal laser scanning microscopy (CLSM) images presented that strong DOX green fluorescence from the DOX/CS ${ }_{100 \mathrm{~K}}-\mathrm{PEG}_{2}$ micelles, which was located in cytoplasm after $12 \mathrm{~h}$ incubation as shown in Figure 6A. Additionally, partial DOX green fluorescence was found in cell nuclei, indicating the DOX/CS ${ }_{100 \mathrm{~K}}-\mathrm{PEG}_{2}$ micelles could be able to diffuse in cell nuclei in cytoplasm of the live cells after $12 \mathrm{~h}$ incubation. It is worth noting that intracellular DOX fluorescence of the DOX/CS $100 \mathrm{~K}-\mathrm{PEG}_{2}$ micelles mainly located at the cell nuclei after $24 \mathrm{~h}$ incubation, compared to that of $12 \mathrm{~h}$ (Figure 6A). This result revealed the nucleus localization of DOX in tumor cells. Meantime, the morphologies of HepG2 cells treated with the DOX/CS $100 \mathrm{~K}-\mathrm{PEG}_{2}$ micelles after $12 \mathrm{~h}$ incubation showed survived cell morphology, while most cells died after $24 \mathrm{~h}$ incubation with the DOX/CS ${ }_{100 \mathrm{~K}}-\mathrm{PEG}_{2}$ micelles, as shown in bright field of Figure $6 \mathrm{~A}$ and $\mathrm{B}$. This demonstrated that the $\mathrm{DOX} / \mathrm{CS}_{100 \mathrm{~K}}-\mathrm{PEG}_{2}$ micelles presented obvious cytotoxicity toward the cells and showed significant cell inhibition for live cells $[34,35]$, as revealed by the MTT assays. The finding is in accordance with well-known DOX's antitumor activity, which forwardly inserts double helix structure in DNAs and induce single-and double-strand breaks to disrupt the replication and transcription processes 
[36]. Taking above exploration and analysis into consideration, the "off-on" switchable DOX delivery system with $\mathrm{pH}$-responsive properties has been realized owing to the protonation of amine group of chitosan in response to the slightly acidic media.

\section{Conclusions}

In summary, a facile strategy was developed to fabricate the drug leakage-free DDS by means of the solubility of chitosan in different pH media as an "off-on" switch. The PEGylated chitosan was used as an amphiphilic precursor for molecular self-assembly by hydrophobic interaction in PBS. The resulting DOX/CS $100 \mathrm{~K}-\mathrm{PEG}_{2}$ micelles possess well-defined core-shell structure and a narrow size distribution. More importantly, they also own highly stability at physiological $\mathrm{pH}$ with ultra-low drug leakage of only $2.32 \%$ within $60 \mathrm{~h}$, and burst release properties in a stimulated microenvironment of tumor tissues, realizing the "off-on" switchable release properties. With the help of biocompatible PEGylated chitosan, the DDS possesses remarkable biocompatibility, and hydrophobic anticancer DOX could be efficiently and rapidly transported into cell nuclei of tumor cells and showed significant cell inhibition. Meantime, after the $\mathrm{pH}$-triggered intracellular release of DOX at the tumor microenvironment, the DOX/CS ${ }_{100 \mathrm{~K}}-\mathrm{PEG}_{2}$ micelles could transform into the water-soluble $\mathrm{CS}_{100 \mathrm{~K}}-\mathrm{PEG}_{2}$, which could be degraded, and then eliminated by metabolic system. So the site-specific delivery of anti-cancer drug could be efficiently achieved in the tumor tissues through the proposed easy-to-prepare biocompatible 
drug leakage-free chitosan-based DDS.

\section{Acknowledgments}

This project was granted financial support from the National Natural Science

Foundation of China (Grant No. 20904017), the Program for New Century Excellent

Talents in University of the Ministry of Education of China (Grant No.

NCET-09-0441), the "Chunhui Project" from the Ministry of Education of China

(Grant no. Z2012116), and the National Science Foundation for Fostering Talents in

Basic Research of the National Natural Science Foundation of China (Grant No.

J1103307).

\section{References}

[1] Y.H. Wang, S.Y. Song, J.H. Liu, D.P. Liu, H.J. Zhang, ZnO-functionalized upconverting nanotheranostic agent: Multi-modality imaging-guided chemotherapy with on-demand drug release triggered by $\mathrm{pH}$, Angew. Chem.-Int. Ed. 54 (2) (2015) 536-540.

[2] L.E. Gerweck, K. Seetharaman, Cellular $\mathrm{pH}$ gradient in tumor versus normal tissue: potential exploitation for the treatment of cancer, Cancer Res. 56 (6) (1996) 1194-1198.

[3] R. de la Rica, D. Aili, M.M. Stevens, Enzyme-responsive nanoparticles for drug release and diagnostics, Adv. Drug Deliv. Rev. 64 (11) (2012) 967-978.

[4] R.D. Issels, Hyperthermia adds to chemotherapy, Eur. J. Cancer 44 (17) (2008) $2546-2554$.

[5] E. Dressaire, R. Bee, D.C. Bell, A. Lips, H.A. Stone, Interfacial polygonal 
nanopatterning of stable microbubbles, Science 320 (5880) (2008) 1198-1201.

[6] X.B. Zhao, P. Liu, Reduction-responsive core-shell-corona micelles based on triblock copolymers: novel synthetic strategy, characterization, and application as a tumor microenvironment-responsive drug delivery system, ACS Appl. Mater. Interfaces 7 (1) (2015) 166-174.

[7] K. Ulbrich, T. Etrych, P. Chytil, M. Pechar, M. Jelinkova, B. Rihova, Polymeric anticancer drugs with pH-controlled activation, Int. J. Pharm. 277 (1-2) (2004) $63-72$.

[8] W. Xiong, W. Wang, Y. Wang, Y.B. Zhao, H.B. Chen, H.B. Xu, X.L. Yang, Dual temperature/pH-sensitive drug delivery of poly $(\mathrm{N}$-isopropylacrylamide-co-acrylic acid) nanogels conjugated with doxorubicin for potential application in tumor hyperthermia therapy, Colloid Surf.-B: Biointerfiace 84 (2) (2011) 447-453.

[9] D. Li, J. Tang, C. Wei, J. Guo, S.L. Wang, D. Chaudhary, C.C. Wang, Doxorubicin-conjugated mesoporous magnetic colloidal nanocrystal clusters stabilized by polysaccharide as a smart anticancer drug vehicle, Small 8 (17) (2012) 2690-2697.

[10] L.F. Cheng, Q. Hu, L. Cheng, W. Hu, M. Xu, Y.Q. Zhu, L. Zhang, D.W. Chen, Construction and evaluation of PAMAM-DOX conjugates with superior tumor recognition and intracellular acid-triggered drug release properties, Colloid Surf.-B: Biointerfiace 136 (2015) 37-45.

[11] X. Jia, X.B. Zhao, K. Tian, T.T. Zhou, J.G. Li, R.N. Zhang, P. Liu, Fluorescent Copolymer-Based Prodrug for pH-Triggered Intracellular Release of DOX, Biomacromolecules 16 (11) (2015) 3624-3631.

[12] L.D. Chen, Y.A. Xue, X.Y. Xia, M.F. Song, J. Huang, H. Zhang, B. Yu, S.H. Long, Y.P. Liu, L. Liu, S.W. Huang, F.Q. Yu, A redox stimuli-responsive 
superparamagnetic nanogel with chemically anchored DOX for enhanced anticancer efficacy and low systemic adverse effects J. Mater. Chem. B 3 (46) (2015) 8949-8962.

[13] X. Du, L. Xiong, S. Dai, S.Z. Qiao, $\gamma$-PGA-Coated Mesoporous Silica Nanoparticles with Covalently Attached Prodrugs for Enhanced Cellular Uptake and Intracellular GSH-Responsive Release, Adv. Healthcare Mater. 4 (7) (2015) $771-781$.

[14] O. Mezghrani, Y. Tang, X. Ke, Y. Chen, D.R. Hu, J.S. Tu, L. Zhao, N. Bourkaib, Hepatocellular carcinoma dually-targeted nanoparticles for reduction triggered intracellular delivery of doxorubicin, Int. J. Pharm. 478 (2) (2015) 553-568.

[15] C.H. Lu, M. Xing, W. Zhong, Shell cross-linked and hepatocyte-targeting nanoparticles containing doxorubicin via acid-cleavable linkage, Nanomedicine: NBM 7 (1) (2011) 80-87.

[16] Y. Lee, S.Y. Park, H. Mok, T.G. Park Synthesis,Characterization,Antitumor Activity of Pluronic Mimicking Copolymer Micelles Conjugated with Doxorubicin via Acid-Cleavable Linkage, Bioconjugate Chem. 19 (2) (2008) $525-531$.

[17] H.Y. Tang, J. Guo, Y. Sun, B.S. Chang, Q.G. Ren, W.L. Yang, Facile synthesis of $\mathrm{pH}$ sensitive polymer-coated mesoporous silica nanoparticles and their application in drug delivery, Int. J. Pharm. 421 (2) (2011) 388-396.

[18] X. Chen, A.H. Soeriyadi, X. Lu, S.N. Sagnella, M. Kavallaris, J.J. Gooding, Dual Bioresponsive Mesoporous Silica Nanocarrier as an "AND” Logic Gate for Targeted Drug Delivery Cancer Cells, Adv. Funct. Mater. 24 (44) (2014) 6999-7006.

[19] G.-F. Luo, W.-H. Chen, Y. Liu, J. Zhang, S.-X. Cheng, R.-X. Zhuo, X.-Z. Zhang, 
Charge-reversal plug gate nanovalves on peptide-functionalized mesoporous silica nanoparticles for targeted drug delivery, J. Mater. Chem. B 1 (41) (2013) $5723-5732$.

[20] J. Dai, Q.Q. Li, W.Y. Liu, S.D. Lin, Y.Y. Hao, C. Zhang, X.T. Shuai, Synthesis and characterization of cell-microenvironment-sensitive leakage-free gold-shell nanoparticles with the template of interlayer-crosslinked micelles, Chem. Commun. 51 (47) (2015) 9682-9685.

[21] M. Prabaharan, Chitosan-based nanoparticles for tumor-targeted drug delivery, Int. J. Bio. Macromol. 72 (2015) 1313-1322.

[22] L. Casettari, D. Vllasaliu, E. Castagnino, S. Stolnik, S. Howdle, L. Illum, PEGylated chitosan derivatives: Synthesis, characterizations and pharmaceutical applications, Prog. Polym. Sci. 37 (5) (2012) 659-685.

[23] D. Torrecilla, M.V. Lozano, E. Lallana, J.I. Neissa, R. Novoa-Carballal, A. Vidal, E. Fernandez-Megia, D. Torres, R. Riguera, M.J. Alonso, F. Dominguez, Anti-tumor efficacy of chitosan-g-poly(ethylene glycol) nanocapsules containing docetaxel: Anti-TMEFF-2 functionalized nanocapsules vs. non-functionalized nanocapsules, Eur. J. Pharm. Biopharm. 83 (3) (2013) 330-337.

[24] M.M. Jia, Y. Li, X.R. Yang, Y.C. Huang, H.J. Wu, Y. Huang, J.Y. Lin, Y.X. Li, Z.Q. Hou, Q.Q. Zhang, Development of both methotrexate and mitomycin C loaded PEGylated chitosan nanoparticles for targeted drug codelivery and synergistic anticancer effect, ACS Appl. Mater. Interfaces 6 (14) (2014) $11413-11423$.

[25] U. Termsarasab, I.-S. Yoon, J.-H. Park, H.T. Moon, H.-J. Cho, D.-D. Kim, Polyethylene glycol-modified arachidyl chitosan-based nanoparticles for prolonged blood circulation of doxorubicin, Int. J. Pharm. 464 (1-2) (2014) 
$127-134$.

[26] L.E. Scheeren, D.R. Nogueira, L.B. Macedo, M.P. Vinardell, M. Mitjans, M.R. Infante, C.M.B. Rolim, PEGylated and poloxamer-modified chitosan nanoparticles incorporating a lysine-based surfactant for $\mathrm{pH}$-triggered doxorubicin release, Colloid Surf. B: Biointerface 138 (2016) 117-127.

[27] H. Zhang, S. Mardyani, W.C.W. Chan, E. Kumacheva, Design of biocompatible chitosan microgels for targeted $\mathrm{pH}$-mediated intracellular release of cancer therapeutics, Biomacromolecules 7 (5) (2006) 1568-1572.

[28] B.B. Hsu, S.R. Hagerman, K. Jamieson, J. Veselinovic, N. O’Neill, E. Holler, J.Y. Ljubimova, P.T. Hammond, Multilayer films assembled from naturally-derived materials for controlled protein release, Biomacromolecules 15 (6) (2014) 2049-2057.

[29] X.B. Zhao, P. Liu, pH-sensitive fluorescent hepatocyte-targeting multilayer polyelectrolyte hollow microspheres as a smart drug delivery system, Mol. Pharmaceutics 11 (5) (2014) 1599-1610.

[30] X.B. Zhao, P. Liu, Preparation of aggregation-resistant biocompatible superparamagnetic noncovalent hybrid multilayer hollow microspheres for controlled drug release, Mol. Pharmaceutics 9 (11) (2012) 3330-3339.

[31] G.Y. Mao, W.J. Yang, F.X. Bu, D.M. Jiang, Z.J. Zhao, Q.H. Zhang, Q.C. Fang, J.S. Jiang, One-step hydrothermal synthesis of $\mathrm{Fe}_{3} \mathrm{O}_{4} @ \mathrm{C}$ nanoparticles with great performance in biomedicine, J. Mater. Chem. B 2 (28) (2014) 4481-4488.

[32] H.Y. Wen, C.Y. Dong, H.Q. Dong, A.J. Shen, W.J. Xia, X.J. Cai, Y.Y. Song, X.Q. Li, Y.Y. Li, D.L. Shi, Engineered redox-responsive PEG detachment mechanism in PEGylated nano-graphene oxide for intracellular drug delivery, Small 8 (5) (2012) 760-769. 
[33] Y.Q. Zhu, L. Liu, J.Z. Du, Probing into Homopolymer Self-Assembly: How Does Hydrogen Bonding Influence Morphology? Macromolecules 46 (1) (2013) 194-203.

[34] K.M. Tewey, T.C. Rowe, L. Yang, B.D. Halligan, L.F. Liu, Adriamycin-induced DNA damage mediated by mammalian DNA topoisomerase II, Science 226 (4673) (1984) 466-468.

[35] Z.Y. Zhang, Y.D. Xu, Y.Y. Ma, L.L. Qiu, Y. Wang, J.L. Kong, H.M. Xiong, Biodegradable ZnO@polymer Core-Shell Nanocarriers: pH-Triggered Release of Doxorubicin In Vitro, Angew. Chem. Int. Ed. 52 (15) (2013) 4127-4131.

[36] L. Zhou, R. Cheng, H.Q. Tao, S.B. Ma, W.W. Guo, F.H. Meng, H.Y. Liu, Z. Liu, Z.Y. Zhong, Endosomal pH-Activatable Poly(ethylene oxide)-graft-Doxorubicin Prodrugs: Synthesis, Drug Release, and Biodistribution in Tumor-Bearing Mice, Biomacromolecules 12 (5) (2011) 1460-1467. 


\section{Figure Captions}

Scheme 1. Schematic diagram of the formation, and DOX release from the DOX/CS-PEG micelles, triggered by the slightly acidic media in tumor cells.

Scheme 2. The synthesis route of CS-PEG.

Figure 1. FT-TR spectra of CS, DOX, CS-PEG, and DOX/CS ${ }_{100 \mathrm{~K}}-\mathrm{PEG}_{2}$ micelles (A), UV-vis spectra of DOX/CS $50 \mathrm{k}-\mathrm{PEG}, \mathrm{DOX} / \mathrm{CS}_{100 \mathrm{~K}}-\mathrm{PEG}_{1}, \mathrm{DOX} / \mathrm{CS}_{100 \mathrm{~K}}-\mathrm{PEG}_{2}$, DOX/CS ${ }_{100 \mathrm{~K}}-\mathrm{PEG}_{3}$ and DOX/CS $300 \mathrm{k}-\mathrm{PEG}$ in neutral media (B), fluorescent emission spectra of DOX/CS $50 \mathrm{k}-\mathrm{PEG}, \mathrm{DOX} / \mathrm{CS}_{100 \mathrm{~K}}-\mathrm{PEG}_{1}, \mathrm{DOX} / \mathrm{CS}_{100 \mathrm{~K}}-\mathrm{PEG}_{2}$, DOX/CS $100 \mathrm{~K}-\mathrm{PEG}_{3}$ and DOX/CS $300 \mathrm{k}-\mathrm{PEG}$ in neutral media $(\mathrm{C})$, and cumulative DOX release from the DOX/CS ${ }_{100 \mathrm{~K}}-\mathrm{PEG}_{2}$ micelles in $\mathrm{PBS}(\mathrm{pH}=7.4), \mathrm{PBS}(\mathrm{pH}=6.5)$ and PBS $(\mathrm{pH}=5.0)$ at $37^{\circ} \mathrm{C}(\mathrm{D})$.

Figure 2. The TEM and DLS results of: (a) DOX/CS $50 \mathrm{~K}-\mathrm{PEG}$ micelles, (b) DOX/CS ${ }_{100 \mathrm{~K}}-\mathrm{PEG}_{1}$ micelles, (c) DOX/CS $300 \mathrm{~K}-\mathrm{PEG}$ micelles, (d) DOX/CS ${ }_{100 \mathrm{~K}}-\mathrm{PEG}_{2}$ micelles, and (e) DOX/CS ${ }_{100 \mathrm{~K}}-\mathrm{PEG}_{3}$ micelles, in PBS (pH 6.8); (f) $\mathrm{DOX} / \mathrm{CS}_{100 \mathrm{~K}}-\mathrm{PEG}_{2}$ micelles in PBS (pH 5.0).

Figure 3. The DLS result and TEM image of DOX/CS $100 \mathrm{~K}-\mathrm{PEG}_{2}$ micelles in PBS $(\mathrm{pH}$ 7.4).

Figure 4. The TEM images of the $\mathrm{CS}_{100 \mathrm{~K}}-\mathrm{PEG}_{2}$ micelles in PBS (pH 7.4 (a) and $\mathrm{pH}$ $5.0(b))$

Figure 5. Cytocompatibility of DOX/CS $100 \mathrm{~K}-\mathrm{PEG}_{2}$, and antitumor capability of DOX/CS ${ }_{100 K}-\mathrm{PEG}_{2}$ determined by standard MTT assay. Data are presented as the mean \pm standard deviation $(\mathrm{SD} ; \mathrm{n}=5)$

Figure 6. CLSM images of cellular uptake of the DOX/CS ${ }_{100 \mathrm{~K}}-\mathrm{PEG}_{2}$ micelles after 12 h (A) and $24 \mathrm{~h}$ (B) incubation. HepG2 cells were stained by Hoechst, The concentration of DOX/CS ${ }_{100 \mathrm{~K}}-\mathrm{PEG}_{2}$ micelles was $20 \mu \mathrm{g} / \mathrm{mL}$. 


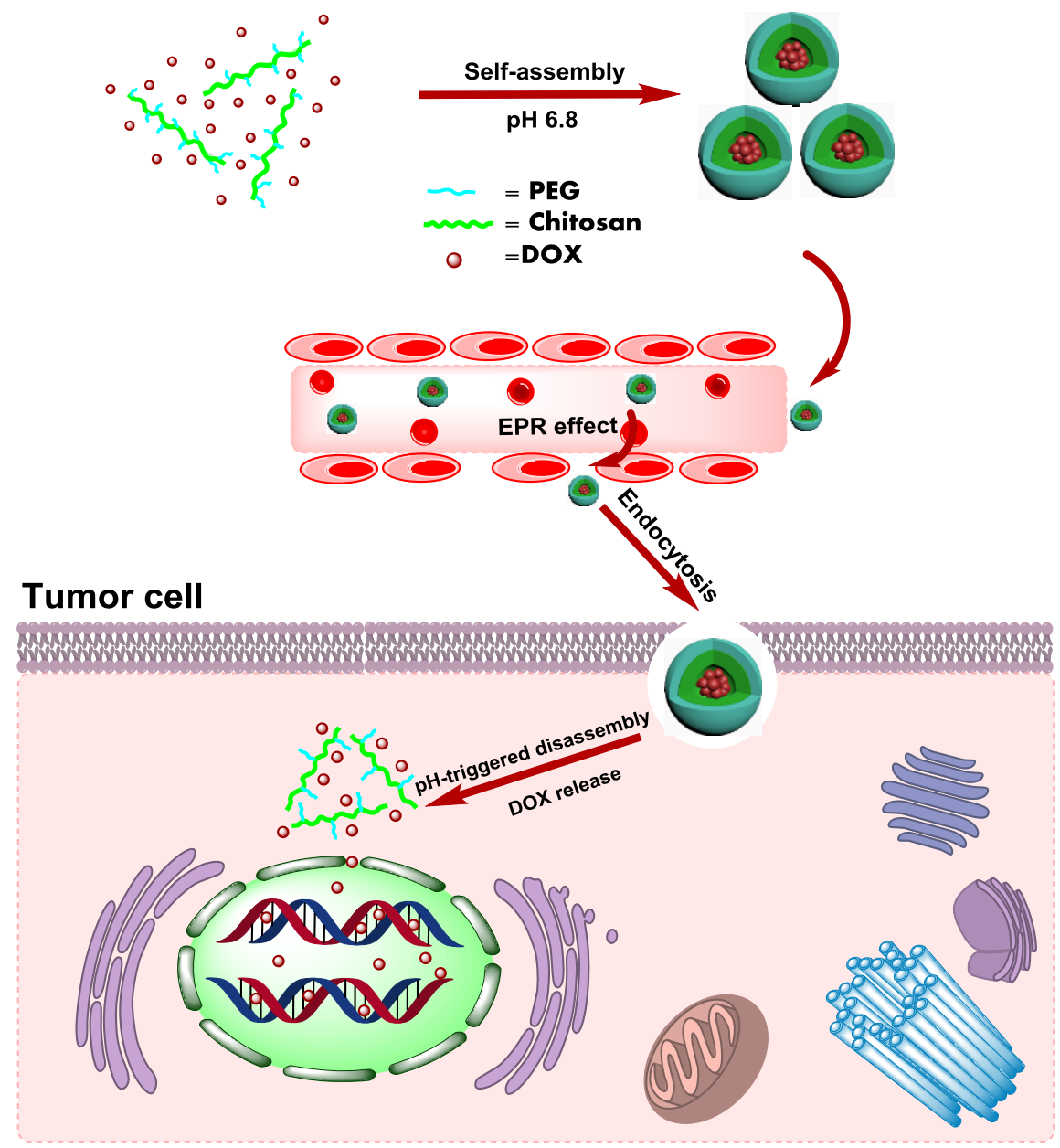

Scheme 1. Schematic diagram of the formation, and DOX release from the DOX/CS-PEG micelles, triggered by the slightly acidic media in tumor cells. 


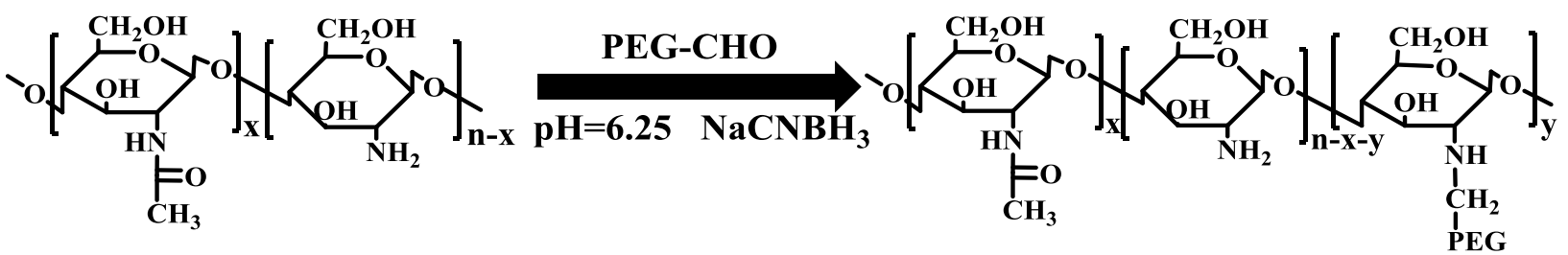

Scheme 2. The synthesis route of CS-PEG. 

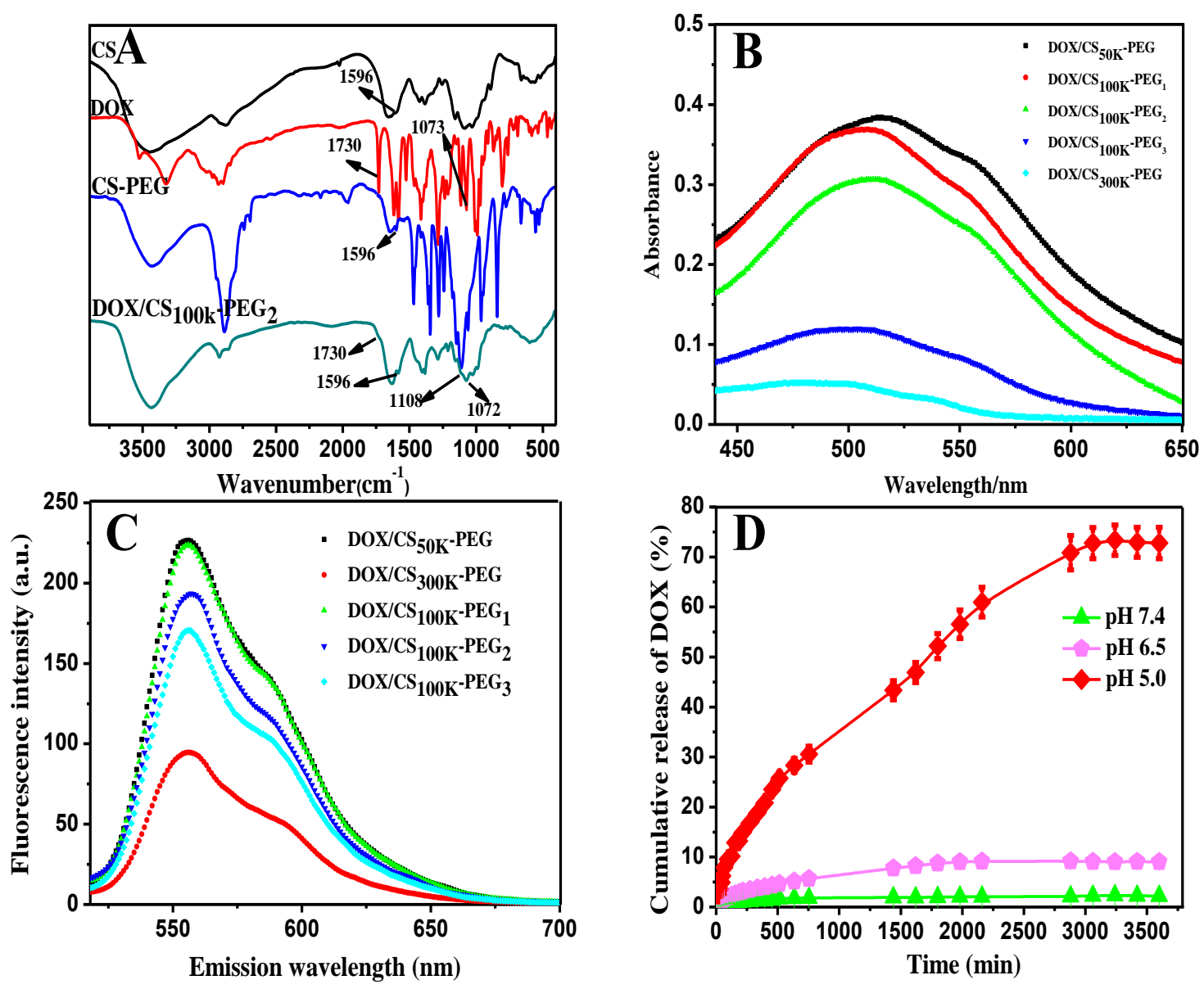

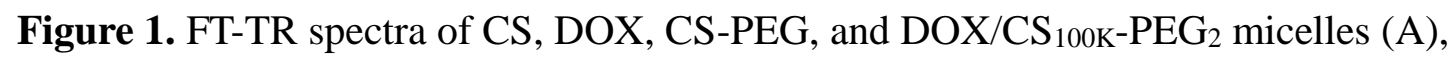
UV-vis spectra of DOX/CS $50 \mathrm{k}-\mathrm{PEG}, \mathrm{DOX} / \mathrm{CS}_{100 \mathrm{~K}}-\mathrm{PEG}_{1}, \mathrm{DOX} / \mathrm{CS}_{100 \mathrm{~K}}-\mathrm{PEG}_{2}$, DOX/CS ${ }_{100 \mathrm{~K}}-\mathrm{PEG}_{3}$ and $\mathrm{DOX} / \mathrm{CS}_{300 \mathrm{k}}-\mathrm{PEG}$ in neutral media (B), fluorescent emission spectra of DOX/CS $50 k-P E G$, DOX/CS ${ }_{100 K}-\mathrm{PEG}_{1}, \mathrm{DOX} / \mathrm{CS}_{100 \mathrm{~K}}-\mathrm{PEG}_{2}$, DOX/CS $100 \mathrm{~K}-\mathrm{PEG}_{3}$ and DOX/CS $300 \mathrm{k}-\mathrm{PEG}$ in neutral media $(\mathrm{C})$, and cumulative DOX release from the $\mathrm{DOX} / \mathrm{CS}_{100 \mathrm{~K}}-\mathrm{PEG}_{2}$ micelles in $\mathrm{PBS}(\mathrm{pH}=7.4), \mathrm{PBS}(\mathrm{pH}=6.5)$ and $\operatorname{PBS}(\mathrm{pH}=5.0)$ at $37^{\circ} \mathrm{C}(\mathrm{D})$. 


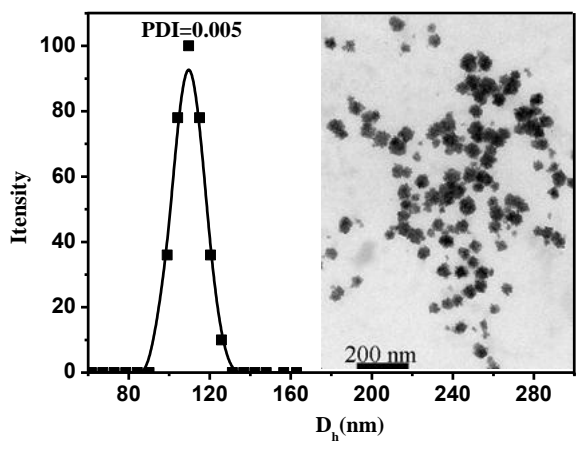

(a)

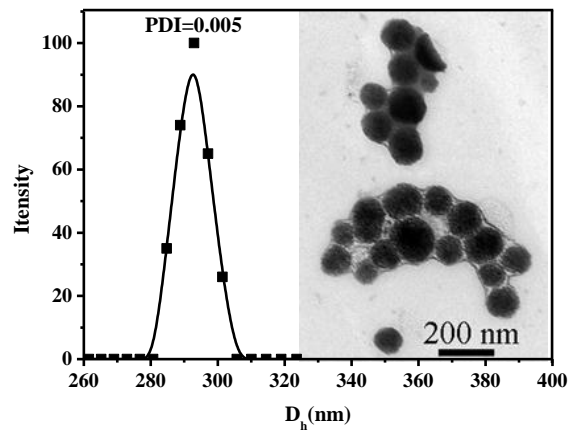

(c)

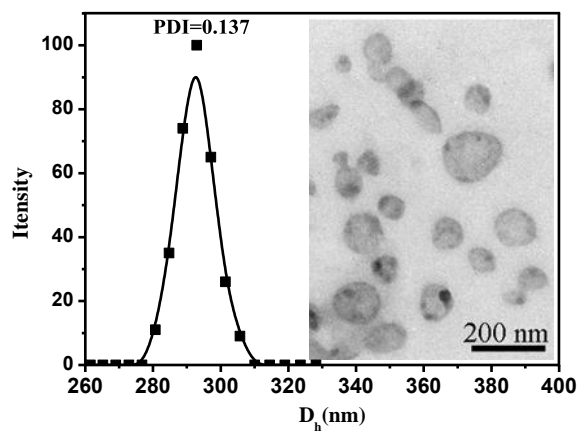

(e)

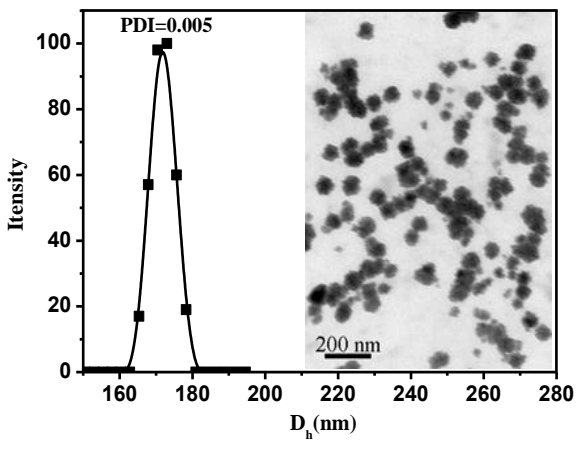

(b)

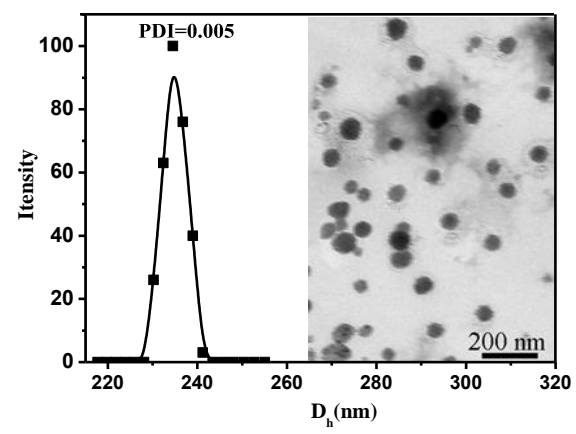

(d)

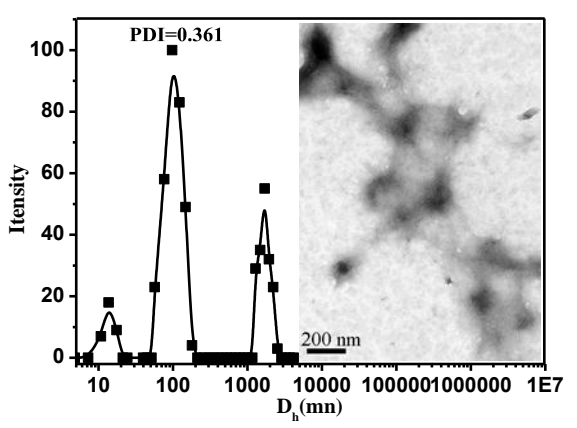

(f)

Figure 2. The TEM and DLS results of: (a) DOX/CS $50 \mathrm{~K}-\mathrm{PEG}$ micelles, (b)

DOX/CS ${ }_{100 K}-P_{E G}$ micelles, (c) DOX/CS $300 \mathrm{~K}-\mathrm{PEG}$ micelles, (d) DOX/CS ${ }_{100 \mathrm{~K}}-\mathrm{PEG}_{2}$ micelles, and (e) DOX/CS $100 \mathrm{~K}-\mathrm{PEG}_{3}$ micelles, in PBS (pH 6.8); (f) DOX/CS $100 \mathrm{~K}-\mathrm{PEG}_{2}$ micelles in PBS (pH 5.0). 

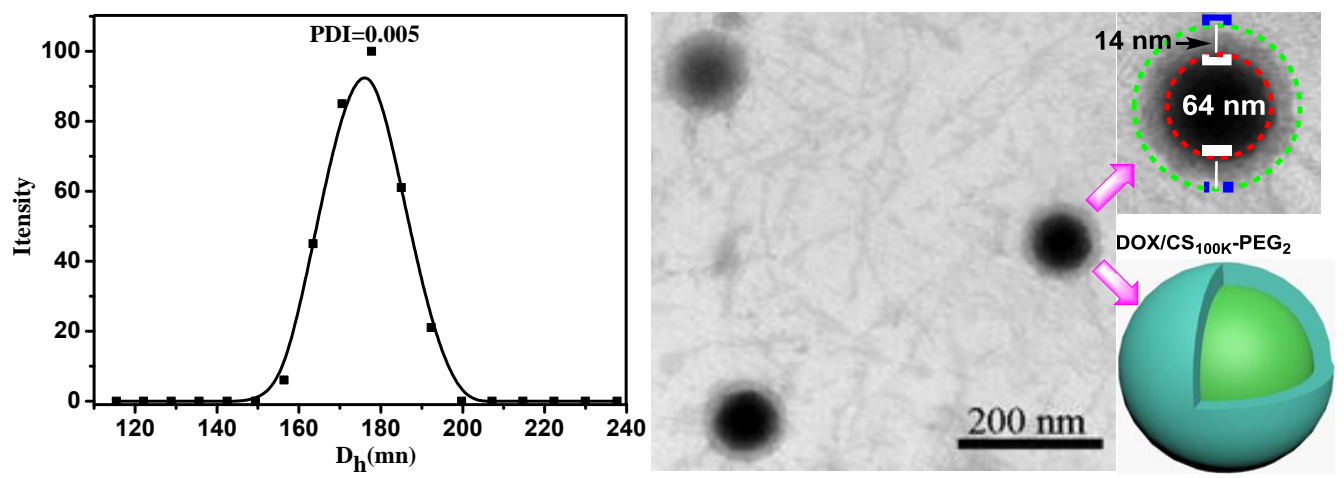

Figure 3. The DLS result and TEM image of DOX/CS ${ }_{100 \mathrm{~K}}-\mathrm{PEG}_{2}$ micelles in $\mathrm{PBS}(\mathrm{pH}$

7.4). 


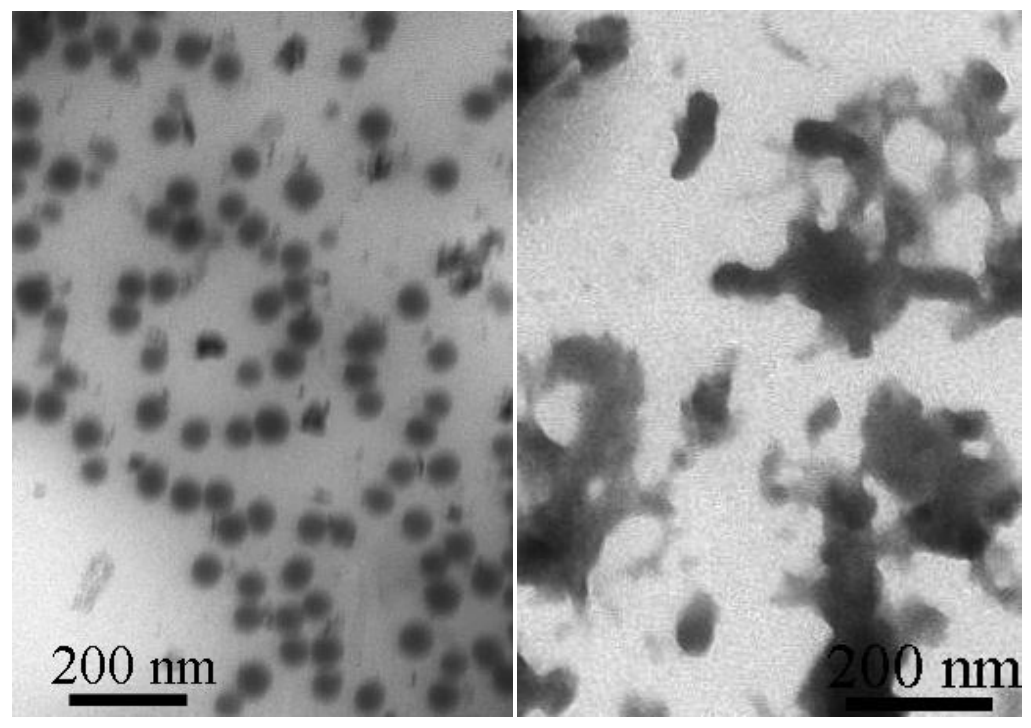

(a)

(b)

Figure 4. The TEM images of the $\mathrm{CS}_{100 \mathrm{~K}}-\mathrm{PEG}_{2}$ micelles in $\mathrm{PBS}(\mathrm{pH} 7.4$ (a) and $\mathrm{pH}$ $5.0(b))$ 


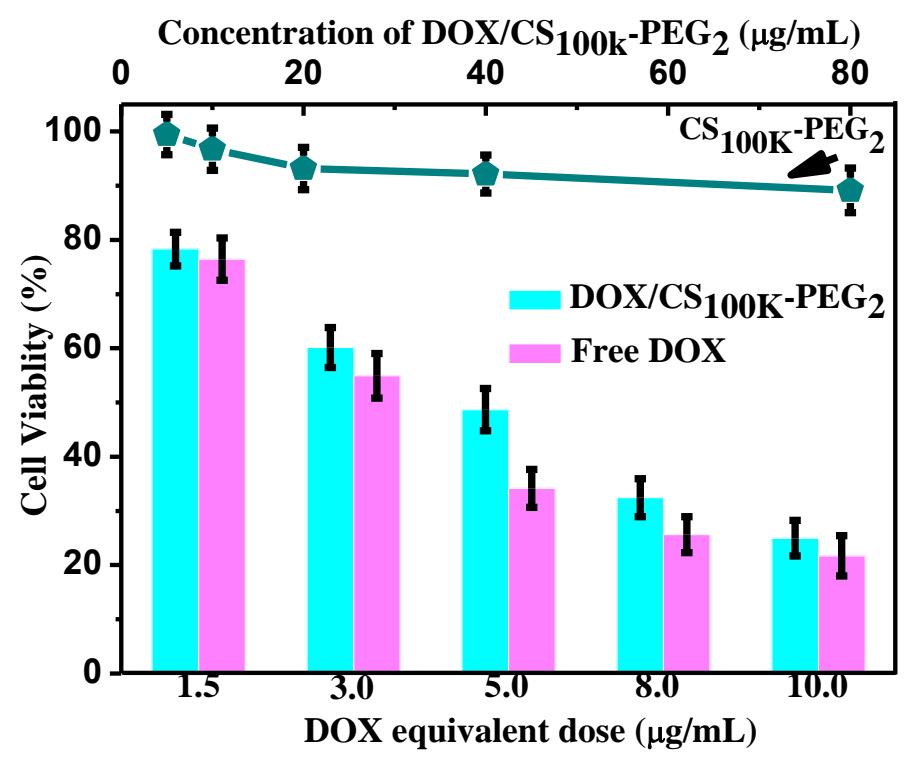

Figure 5. Cytocompatibility of DOX/CS $100 \mathrm{~K}-\mathrm{PEG}_{2}$, and antitumor capability of DOX/CS ${ }_{100 \mathrm{~K}}-\mathrm{PEG}_{2}$ determined by standard MTT assay. Data are presented as the mean \pm standard deviation $(\mathrm{SD} ; \mathrm{n}=5)$. 


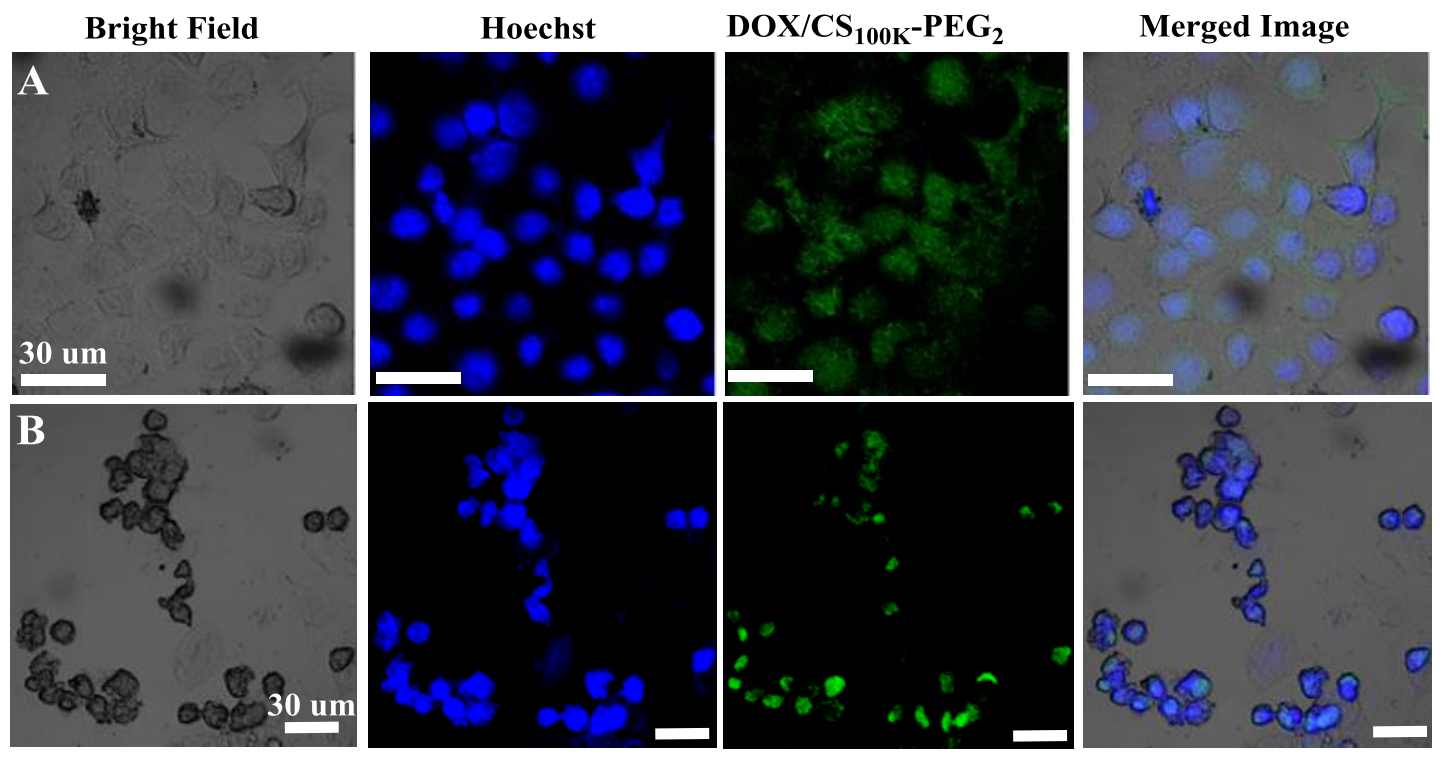

Figure 6. CLSM images of cellular uptake of the $\mathrm{DOX} / \mathrm{CS}_{100 \mathrm{~K}}-\mathrm{PEG}_{2}$ micelles after 12

h (A) and $24 \mathrm{~h}(\mathrm{~B})$ incubation. HepG2 cells were stained by Hoechst, The concentration of DOX/CS ${ }_{100 \mathrm{~K}}-\mathrm{PEG}_{2}$ micelles was $20 \mu \mathrm{g} / \mathrm{mL}$. 


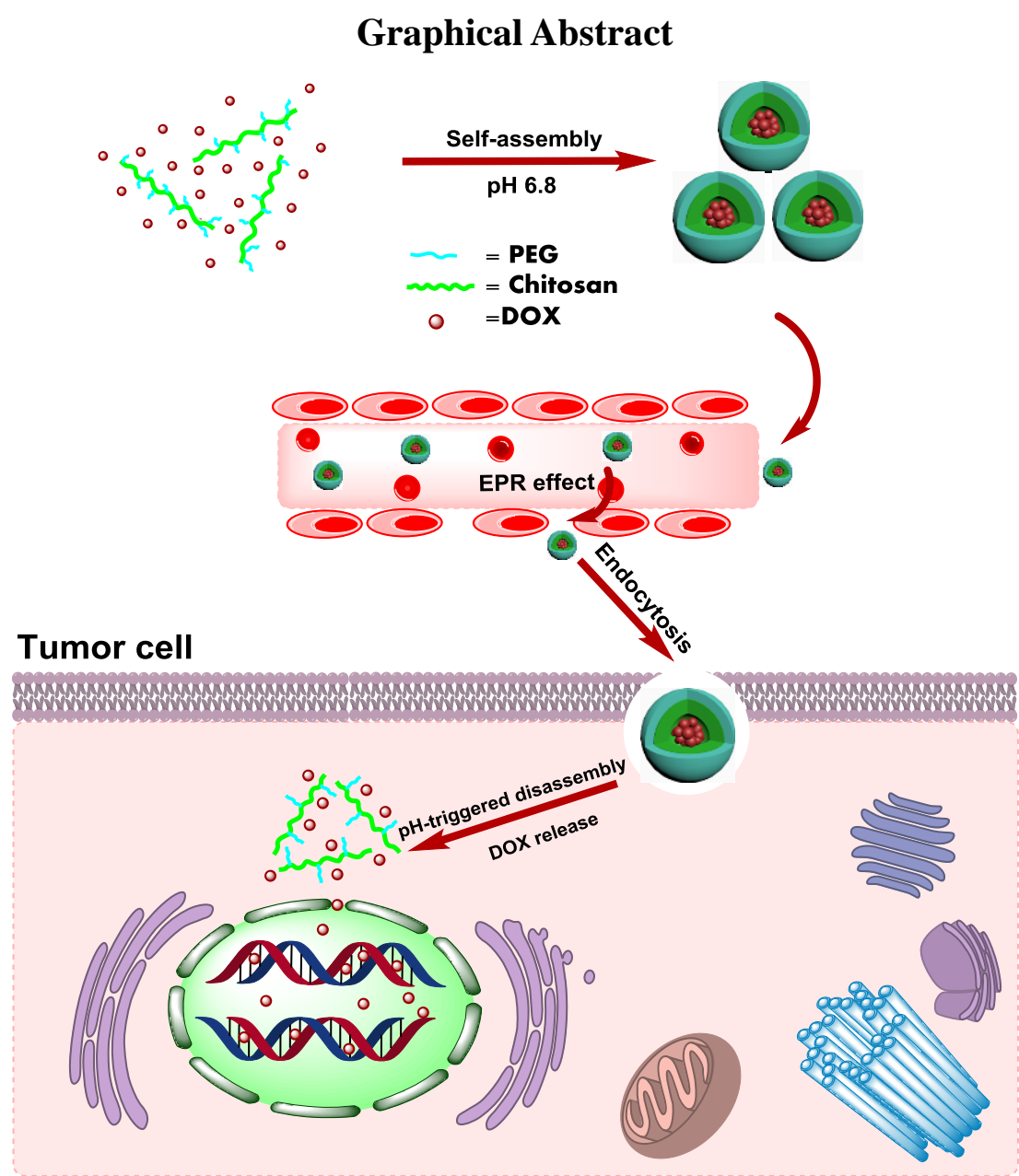

